\title{
Communicating about Climate Change through AMS Student Chapter Activities
}

\author{
Margaret Orr, Dana E. Veron, and Melissa J. B. Rogers
}

\begin{abstract}
AMS student chapter at UD
The University of Delaware's Department of Geography and Spatial Sciences launched a new meteorology and climatology major in the fall of 2015, creating a curriculum for students who are interested in meteorology that follows the guidelines suggested by AMS and NWS. In conjunction with the adoption of this new major, the student AMS chapter at the University of Delaware (UD) was reactivated by six sophomore and junior meteorology and climatology majors in the spring of 2016. These two events allowed the student members to reevaluate the mission and vision of the student chapter.
\end{abstract} The AMS student chapter at UD now has a focus on outreach and education, which includes student presentations on disaster preparedness and fundraising for disaster relief after Hurricane Maria. One of the initial activities developed by the chapter

AFFILIATIONS: ORR—University of Georgia, Athens, Georgia; VerONUniversity of Delaware, Newark, Delaware; Rogers—University of Maryland Center for Environmental Science, Cambridge, Maryland

CORRESPONDING AUTHOR: Dana E. Veron, dveron@udel.edu DOI:10.1175/BAMS-D-18-0245.1

In final form 1 October 2020

C2021 American Meteorological Society

For information regarding reuse of this content and general copyright information, consult the AMS Copyright Policy. is an ongoing outreach and education program in a nearby high school that allows AMS chapter members to share their passion about weather and climate with the next generation of students while improving teaching and presentation skills. They do this by teaching students a climate change game. The student chapter members learned about this game through interaction with a UD faculty member who participated in the Maryland and Delaware Climate Change Education Assessment and Research project (MADE-CLEAR; madeclear.org), which provided K-16 teachers in Maryland and Delaware with climate science and educational support.

\section{The carbon cycle game}

"The Incredible Carbon Journey" is a game developed by NOAA as part of a freely available online activity book (Activity Book: Discover Your Changing World with NOAA; https://oceanservice.noaa.gov/education/discoverclimate/), 
which was developed to familiarize students with the essential principles of climate literacy [U.S. Global Change Research Program (USGCRP); USGCRP 2009]. In the Incredible Carbon Journey game, players assume the role of carbon atoms experiencing the carbon cycle by traveling among the carbon reservoirs in Earth's climate system. The associated content and the use of a model to explain Earth systems and human interactions with them tie into multiple Earth and life standards within the high school level Next Generation Science Standards (NGSS; see "Tying science education standards into the game" sidebar). There are four game stations representing carbon reservoirs in Earth's climate system (biosphere, hydrosphere, lithosphere, and atmosphere). Each station has a cup full of color-coded beads, with colors spe-

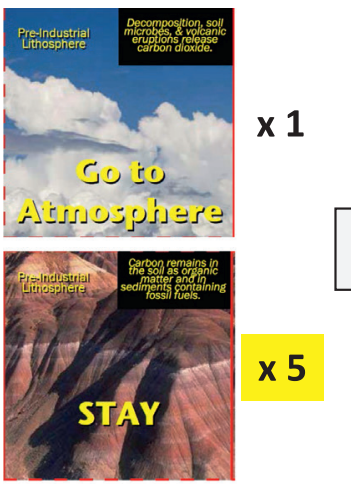

\section{Pre-industrial Carbon Cycle}

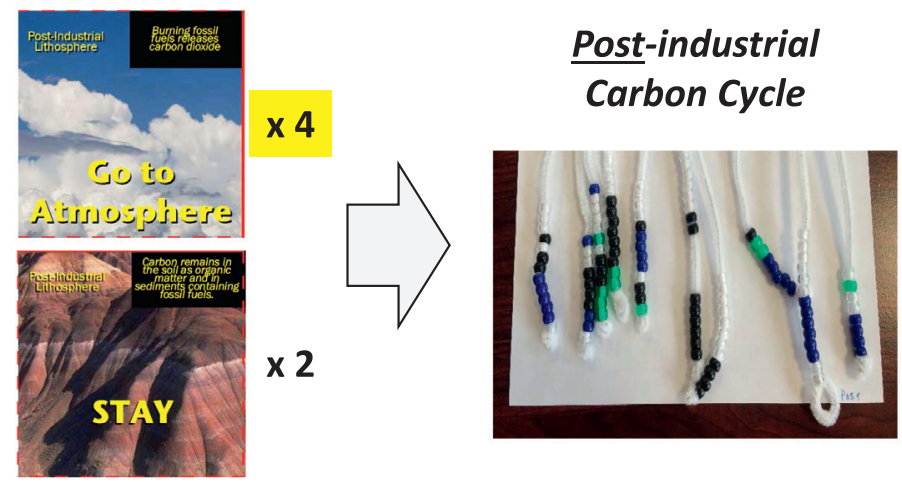

Fig. 2. The difference in the lithosphere die between the first game play (preindustrial carbon cycle) and (bottom) the second game play (postindustrial carbon cycle). The photos were taken during gameplay in a physical meteorology class at UD, showing the pipe cleaners recording the journeys of the carbon atoms for each game. Die faces from Activity Book: Discover Your Changing World with NOAA (https://oceanservice.noaa.gov /education/discoverclimate/). cific to that reservoir (black-lithosphere; green-biosphere; clear-atmosphere; blue-hydrosphere), and a six-sided die also specific to the reservoir that directs the movement of the player acting as a carbon atom (stay in the reservoir, or move elsewhere), represented by the player. The number of faces of each die that directs whether a player stays in that reservoir or moves on is related to the carbon fluxes among reservoirs derived by scientists for the carbon cycle. The game is played twice, once with a preindustrial carbon cycle and once with a postindustrial carbon cycle, with the difference represented in a change in the lithosphere die.

To play the game, the class divides into four equal groups, lining up at each carbon reservoir. The game progresses through a series of rounds governed by rolling a die at each station. The leader of each line rolls that station's die. If the die directs the player who rolled to stay, they pick up a bead the color of their current reservoir and go to the end of the line; if the player is directed to another reservoir, they go to the end of the line at the new reservoir and pick up a bead from their new reservoir. Only the four students at the head of each line roll and move. All other players in line advance one space and pick up a bead from their current reservoir. The game facilitator controls the speed of the rounds to make sure each atom (player) experiences the same time (number of rounds) in the carbon cycle.

Players track their progress through the carbon cycle by threading the beads they gather each round onto a pipe cleaner (Fig. 1). If a line gets really long at one of the reservoirs, students will stay there many rounds before they can roll and may or may not leave depending on that roll. The pattern of beads on a player's pipe cleaner represents the number of rounds, a proxy for residence time that the player spent in each reservoir.

After roughly 20 rounds, the game is over and students compare pipe cleaners: evidence of their "journeys" through the carbon cycle. Figure 2 (top) shows the faces of the lithosphere cube for the game, with the resulting “journeys" recorded on pipe cleaners for 10 students who played in a physical meteorology class at UD. Typically, the pipe cleaners contain long sequences of black and/or blue beads, showing how carbon has long residence times in the lithosphere and hydrosphere. Students also discuss the number of players that are in each reservoir at the end of the game, with most of the students at the lithosphere station. The use of specific evidence to support explanations and the ability to argue about multiple suggested explanations with the support of evidence are important elements 
of the NGSS science and engineering practices.

The game is then played a second time, with a twist. One of the game facilitators secretly swaps the "preindustrial" lithosphere die for a "postindustrial" die; the die for the other three reservoirs remains the same. The preindustrial die has five faces out of six that say "Stay" in the lithosphere, while the postindustrial die only has two faces that say "Stay" and four of which say "Go to the atmosphere" (Fig. 2). Therefore, it is far easier in the second game for a carbon atom to leave the lithosphere and go directly to the atmosphere than in the preindustrial scenario. At the end of the second

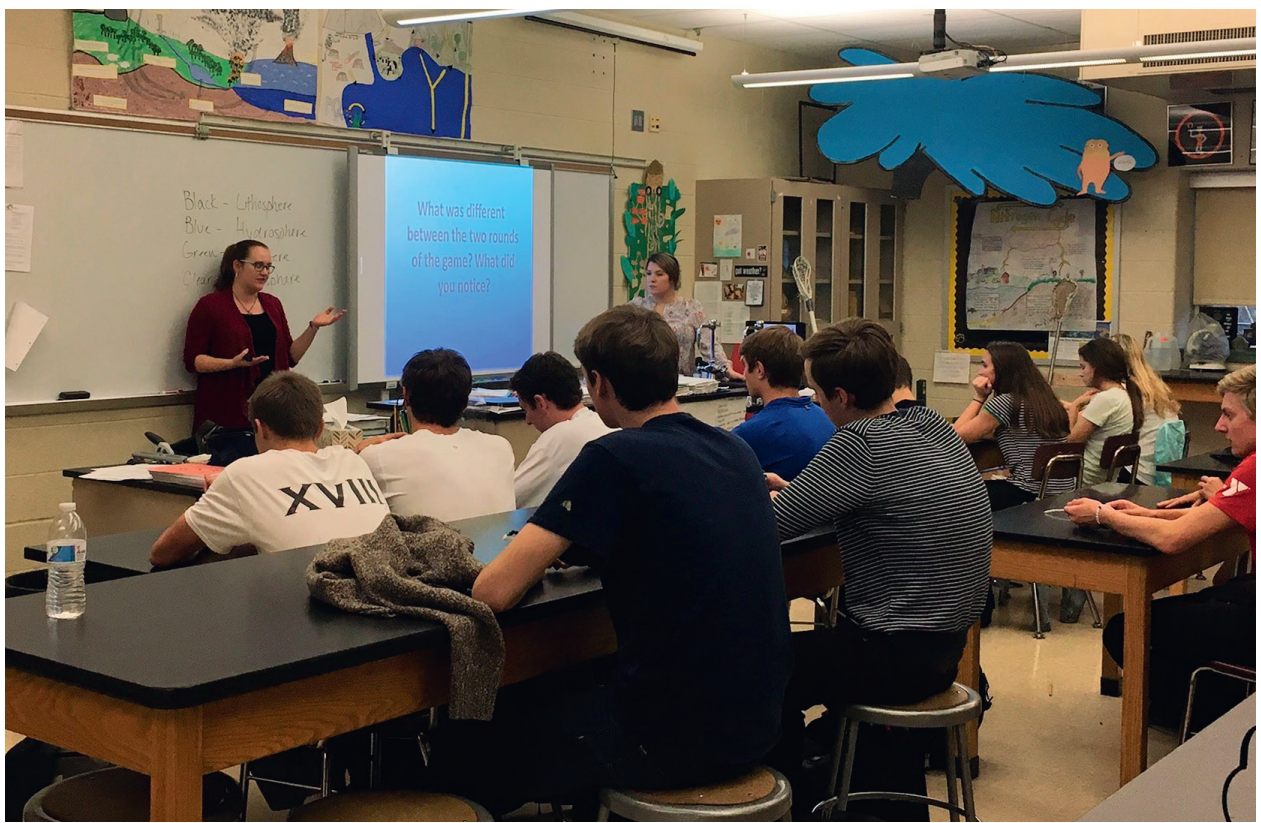

Fig. 3. UD AMS student chapter members leading a discussion at Strath Haven High School in Wallingford, Pennsylvania, on the differences between the two rounds of the game.

the revelation of the "postindustrial" cube. The transfer of carbon from the lithosphere to the atmosphere through the burning of fossil fuels is usually a very abstract concept; however, seeing the change in carbon atom/player distribution between rounds and the difference in pipe cleaners illustrates this concept very clearly-the amount of carbon released to the atmosphere now is 2.5 times the amount released in the preindustrial era. Within a few weeks, the student chapter members were talking seriously about how to introduce the game into other classroom situations.

\section{The outreach activity}

The active participation of students in simulations and games has been linked to greater student retention of concepts than conventional classroom instruction. One of the AMS chapter goals was to develop outreach education to high school and nonmeteorology college students, and the Incredible Carbon Journey game presented a perfect tool. One student, who took on leadership of the chapter's outreach program, said,

I was looking for an activity that would be clear and engaging for students, but also easy for us to implement...we could easily plan one [a short lecture] to go with playing this game and take it to multiple schools.

\footnotetext{
More details about how this game was used as part of an undergraduate professional development activity can be found at www.youtube.com/watch?v=jsdYgmswktA.
} 


\section{Tying science education standards into the game}

The Next Generation Science Standards were released in 2013

(National Research Council 2013). The NGSS describe what students should know and be able to do in science and engineering in order to make sense of the world and participate as a science-literate citizen. The NGSS were designed to support student learning of core ideas in life science, physical science, Earth and space science, and engineering through students' own application of science and engineering practices such as analyzing and interpreting data and engaging in argument through evidence. Based on the National Research Council's Framework for K-12 Science Education, the NGSS included some core ideas such as climate change, not previously common in the U.S. classroom. At the middle and high school levels, elements of climate change appear in all the NGSS strands, specifically related to the interactions of electromagnetic radiation with Earth's atmosphere, photosynthesis and ecosystems, Earth systems, and the impact of human activity on ecosystems and Earth systems.

Delaware was a lead state in the NGSS development and adopted the standards as the state science standards in fall 2013. Schools and teachers are still working toward integrating these topics into their curriculum. Research by Hestness et al. (2014) indicated that some teachers may have extensive knowledge in appropriate content, but that "many teachers report that they feel underprepared...to fully address climate change science in their classrooms." As NGSS-aligned curriculum becomes more available and integrated into schools, this situation should improve.

This student also maintains a close relationship with her former high school environmental science teacher; through this relationship, the AMS chapter was invited to give a presentation in an AP environmental science class of eleventh and twelfth graders. For this inaugural outreach activity, two AMS students visited Strath Haven High School in nearby Wallingford, Pennsylvania, to present the game in the fall semester of 2016. This was the start of the chapter's outreach activities for high school students.
To add more information about climate science to their outreach efforts and keep to the traditional 80-90-min class length used in area middle and high schools, the AMS chapter students created a slide presentation and lecture to bookend gameplay (Fig. 3). The additional presentation materials allowed students and teachers to see how the learning outcomes of the game relate to their broader class goals and impact them as individuals.

The presentation begins with a brief overview of the carbon cycle, highlighting the four carbon reservoirs represented by the game, and then instructs students how to play. After the game, student chapter members explain the connection between increased $\mathrm{CO}_{2}$ in the atmosphere and the changing climate. The composition of the postgame presentation has varied slightly depending on which members are facilitating the outreach event. This is one of the benefits of this outreach model-it can be modified to allow student members to speak to their individual areas of interest or expertise, and gives more junior meteorology students a chance to get involved as well. For example, when the chapter takes first-semester freshmen on the outreach trip before they have taken any meteorology classes, these students present some of the simpler core slides about the carbon cycle, the basics of climate science, or ways to mitigate climate change. On the other hand, more advanced students have added slides about subjects on which they have written papers or been involved in research, such as paleoclimatology, climate modeling, and storm intensification. This flexibility allows students to develop important communication skills, regardless of their academic level.

At the end of the presentation and before the end of the class period, members answer more general questions from the students. The high school students have asked questions about a variety of topics, such as majoring in meteorology, undergraduate student research, college life in general, noncurricular activities, and what advice AMS students have for someone making the transition to college. Although many of the students in the AP environmental science classes are not planning to pursue college degrees in environmental fields, seeing how meteorology and climate change affect them is a valuable learning experience. Additionally, students may become more interested in what they are learning in their coursework, having seen the passion that AMS students have for the subject.

When the AMS student members presented to fifth graders in the "Dinner with a Scientist" event, they used a short- 
ened version of this presentation that focused on game play and the carbon cycle to adjust to the audience level and shortened time periods. Due to the nature of this outreach event, middle school students also asked career questions such as what meteorologists do during the workday.

\section{Developing sustainability and resiliency (building chapter outreach and student skills)}

This outreach activity has developed further since the first visit to Strath Haven High School. Student members now visit AP environmental science classes every semester to present the game and lecture in groups of 4-5 students. In addition, there is interest from Strath Haven teachers in bringing the game into ninth-grade classrooms. Chapter members have also been invited, through word of mouth about the chapter's outreach, to present the activity to Newark Charter High School biology classes, and Newark Charter Intermediate School's annual Dinner with a Scientist event. In both cases, students were connected through the faculty advisor of UD's student chapter of the AMS; the students have been invited back for subsequent events. This speaks to the power of personal networks, allowing college students to see how beneficial networking can be.

The student members also benefit the greater community around them by presenting to the high school students. Strath Haven AP environmental science teacher Kathy Freeman believes that it is important for her students to learn from people working in environmental fields. She appreciates that

[the AMS students] are in it, you're learning right now the current information about climate science and can really speak to them-about college because most of my students are seniors-but also speak to them about the current topics in climate and answer their questions well.

This outreach activity allows students to put a face to the role of "climate scientist," and engage with the science of climate change in a unique and dynamic manner. High school students may then share what they learned from the activity with friends or parents, which spreads the lesson about climate change beyond the classroom. Additionally, students in these environmental science classes are being exposed to climate change information that will make them more informed citizens and voters.

AMS students have become interested in the outreach activity through word of mouth, as students who have led

\section{Students wanting to reach out}

The authors offer the following tips for chapters interested in outreach to local schools:

- Make use of personal networks to connect with teachers. It helps in building trust with the teacher and you are more likely to be invited into their classroom.

- Contact teachers at the start of the year-or semester, if the school is on a semester class schedule. This allows teachers to easily build your guest lecture into their course plan.

- Give teachers an idea of your guest lecture topic, but ask if there are specific topics they would like to see woven in.

- Create an easily adaptable presentation that can be modified to add different material, or cater to differing grade levels (see note).

- Share your passion for your field—enthusiasm is contagious! NoтE: As schools and colleges adjust their educational practices during the COVID-19 pandemic, the outreach activity also needs to be adapted. Some institutions are fully online, and most K-12 schools are not currently allowing visitors. We are developing a fully online version of the Incredible Carbon Journey game with a die rolling application (https://farkmarnum.github.io/carbon-journey/) to be piloted at UD this fall in an undergraduate climate change course. The AMS student members in the course will then be able to take the revised version into classrooms remotely.

the game have come back to the chapter and raved about their experiences. The game itself has been an effective teaching tool for high school students, but the outreach program has also clearly benefitted the AMS student members. As one member said, "It's one thing to learn something, but you get a much better understanding when you teach the material.” Teaching allows AMS student members to not only better comprehend their own field of study, it helps them develop critical communication skills that are so important to their future professions. One student explained: 
You have to take this technical information and bring it to a level that high school students can understand. We have to make sure to convey what we want to say in a way that is interesting and fun for them, but also has enough depth to make it beneficial to the course material and their learning. And we have to be good at speaking to a crowd, which is especially challenging when it's a crowd of high school students.

One student, who graduated from Strath Haven High School, likes that this outreach project allows her to give back. She said,

So much of my passion for science comes from my experiences in high school. The science department gave me so much, so I love getting to come visit and give back, to share my knowledge and enthusiasm with current students, and to show them where the education they're getting can take them. I think a lot of our other members have also been impacted by their own high school experiences and would feel the same way taking the game back to their alma maters, as is the plan for the future.

The authors encourage undergraduate students and working professionals alike to follow the example of the student chapter of the AMS at UD by reaching out to local teachers and expressing interest in giving a guest lecture or being part of a career-day type event (see "Students wanting to reach out" sidebar). Outreach education is a great way for both of these groups to impact and serve their local community, and for undergraduate students especially, this is an opportunity to develop key communication and networking skills.

Overall, AMS at UD students and local K-12 teachers alike have found this outreach program engaging and beneficial. The authors hope that this model can be effective and fun for other AMS chapters and their local communities as well.

\section{Acknowledgments}

We would like to thank Mark Farnum for the development of the online dice rolling application, which allowed us to continue this work in an online setting during the COVID-19 pandemic. This project was generously supported by a grant from the National Science Foundation Climate Change Education Partnership (DGE-1239758).

\section{FOR FURTHER READING}

Hestness, E., R. McDonald, B. Christopher, W. Breslyn, J. R. McGinnis, and C. Mouza, 2014: Science teacher professional development in climate change education informed by the next generation science standards. J. Geosci. Educ., 62, 319-329, https://doi. org/10.5408/13-049.1.

National Research Council, 2012: A Framework for K-12 Science Education: Practices, Crosscutting Concepts, and Core Ideas. National Academies Press, 400 pp., https://doi.org/10.17226/13165.

_- 2013: Next Generation Science Standards: For States, By States. National Academies Press, 532 pp., https://doi.org/10.17226/18290.

Randel, J. M., B. A. Morris, C. D. Wetzel, and B. V. Whitehill, 1992: The effectiveness of games for educational purposes: A review of recent research. Simul. Gaming, 23, 261-276, https://doi. org/10.1177/1046878192233001.

USGCRP, 2009: Climate literacy: The essential principles of climate science. NOAA Climate Program Office Rep., 17 pp., https://oceanservice.noaa.gov/ education/literacy.html. 